Article

\title{
Catalytic Formation of Lactic and Levulinic Acids from Biomass Derived Monosaccarides through Sn-Beta Formed by Impregnation
}

\author{
Andrew Kohler, Wayne Seames *, Ian Foerster and Clancy Kadrmas \\ Department of Chemical Engineering, University of North Dakota, Grand Forks, ND 58202, USA; \\ ajkohler@iastate.edu (A.K); ian.foerster.1@und.edu (I.F.); kadrmas@gmail.com (C.K.) \\ * Correspondence: wayne.seames@ndus.edu; Tel.: +1-701-777-2958
}

Received: 8 September 2020; Accepted: 14 October 2020; Published: 20 October 2020

check for updates

\begin{abstract}
In the present study, the use of Sn-Beta zeolite to facilitate the conversion of lignocellulosic biomass-derived glucose and xylose into lactic and levulinic acid was explored. The reactions were carried out in a batch reactor using water as the solvent. Water is the preferred solvent over methanol as it reduces downstream product acid recovery and purification complexity. Optimization experiments were performed for reaction temperature and residence time. Under optimized reaction conditions, the Sn-Beta facilitated reaction of a pure sugar solution resulted in lactic acid yields of 13 and $19 \mathrm{wt} \%$ of inlet carbon of glucose and xylose, respectively, plus levulinic acid yields of 18 and $0.8 \mathrm{wt} \%$, respectively. When actual biomass-derived sugar solutions were tested, the yields of lactic acid were significantly higher than those from the optimized model solution experiments with lactic acid yields of $34 \mathrm{wt} \%$. These biomass-derived sugar solutions contained residual levels of $\mathrm{CaSO}_{4}$ from the neutralization step of the hydrolysis process. Further experiments were performed to examine the potential effects from $\mathrm{CaSO}_{4}$ contributing to this increase. It was found that the sulfate ions increased the Brønsted basicity and the calcium increased the Lewis acidity of the reaction solution, and that the combination of both effects increased the conversion of the original sugars into lactic acid. These effects were verified by testing other organic bases to isolate the Brønsted acid neutralization effect and the Lewis acid enhancement effect. The addition of $\mathrm{CaSO}_{4}$ resulted in attractive lactic acid yields, $68 \mathrm{wt} \%$ and $50 \mathrm{wt} \%$ of inlet carbon from pure glucose and xylose solutions, respectively. Increasing the actual corn stover and forage sorghum derived sugars concentration (in water) allowed lactic acids yields of greater than $60 \mathrm{wt} \%$ to be achieved. When the optimized Sn-Beta reaction system was applied to corn stover and forage sorghum mixtures, it was found that the ratio of lactic-to-levulinic acid generated was inversely dependent upon the glucose-to-xylose ratio in the recovered sugar mixture.
\end{abstract}

Keywords: Sn-Beta; calcium sulfate; corn stover; forage sorghum; glucose; xylose

\section{Introduction}

The effects of global climate change have sparked an effort to transition from fossil-fuel based energy to renewable, lower emitting sources. This shift away from a petroleum-based economy trickles down to commodity and specialty chemicals that are produced from nonrenewable sources. Lactic acid is one potential chemical that can be produced renewably and applied to a wide range of industries including cosmetics, food, pharmaceuticals, and plastics [1-4]. Its most common application is to produce polylactic acid (PLA), a biodegradable plastic. Though this process currently requires pure L-lactic acid, racemic mixtures can also produce biodegradable polymers through intermediate conversion to acrylic acid or propylene glycol [2]. 
Fermentation is currently the primary method of producing lactic acid. However, this method has proven to be costly, hindering the ability of its subsequent products to compete with nondegradable fossil fuel analogs [5]. A potential cost saving measure is to produce lactic acid chemically instead of biologically. Previous work has shown that glucose and other sugars can be catalytically transformed into lactic acid or its derivatives in the presence of either water or methanol, with tin-doped beta zeolite (Sn-Beta) having been identified as an attractive catalyst for this reaction [6-8].

Levulinic acid has been a chemical of interest for many years due to its potential as a platform chemical [9]. An industrial scale process was developed by Biofine Renewables to produce levulinic acid using the cellulose and hemicellulose in agricultural residues [10]. The process hydrolyzes the carbohydrates to monomeric sugars and then dehydrates the sugars to form 5-hydroxymethylfurfural (5-HMF). Then, 5-HMF is recovered and sent to a second reactor, yielding levulinic acid.

Starting from previous works, the present study had the following objectives:

1. Advance the conversion efficiency of the reaction for both glucose and xylose into lactic and levulinic acids through a careful study of the effect of residence time, reaction temperature, and substrate sources on catalyst selectivity and product yields.

2. Evaluate the optimum reaction conditions for monomeric sugar mixtures that simulate the typical composition of sugars extracted from: (1) corn stover and (2) forage sorghum.

3. Apply the optimum reaction conditions to actual sugar mixtures derived from corn stover and forage sorghum to evaluate effectiveness.

Sn-Beta is a catalyst that combines tin with a $\mathrm{Si} / \mathrm{Al}$ catalyst. This catalyst facilitates multiple reaction pathways in converting monosaccharides into lactic acid or levulinic acid. At temperatures as low as $110^{\circ} \mathrm{C}$, Lewis acid sites on Sn-Beta catalyzes the isomerization of sugars between their aldo- (e.g., glucose) and keto-form (e.g., fructose) [6,11-13]. This isomerization can be critical, since at temperatures above $150{ }^{\circ} \mathrm{C}$, the monosaccharides undergo retro-aldol condensation [8]. As seen in Figure 1, if a hexose is in the keto-form, it will split to two trioses, 1,3-dihydroxyacetone (DHA) and glyceraldehyde (GLA), which can then be isomerized into lactic acid [7,14]. Conversely, retro-aldol condensation of aldohexoses forms $\mathrm{C}_{2}$ and $\mathrm{C}_{4}$ fragments which cannot produce lactic acid (not shown).

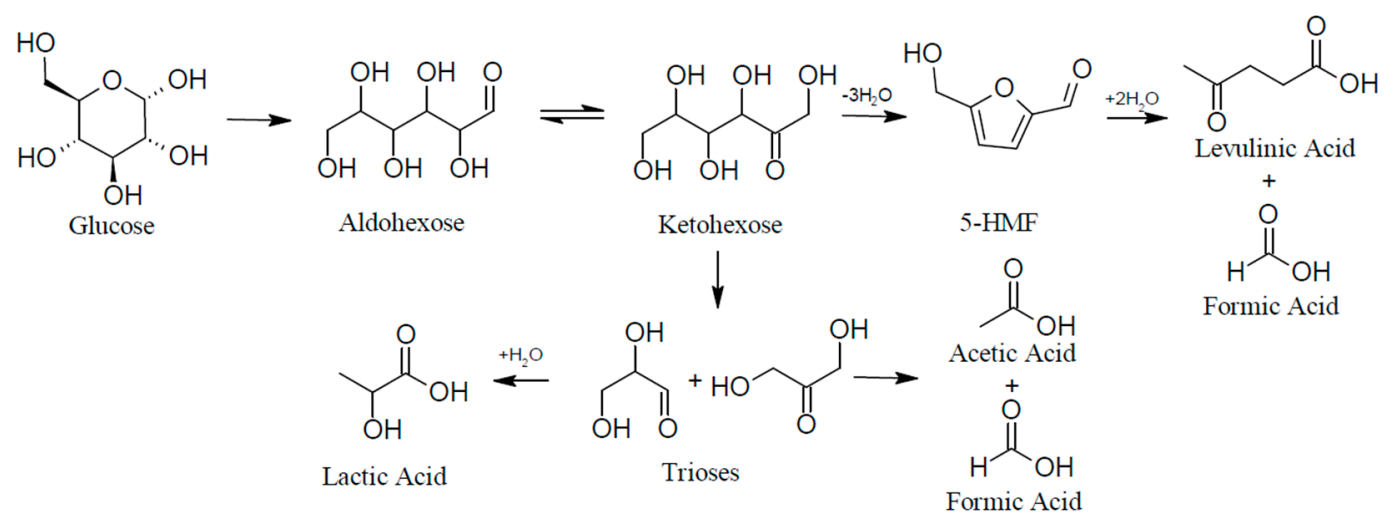

Figure 1. Reaction pathway for hexoses using Sn-Beta.

Lactic acid yields can be hindered by the formation of multiple side-products. In the presence of Brønsted acid sites, ketohexoses can undergo a triple dehydration reaction to form 5-hydroxymethylfurfural (5-HMF) [15]. Double rehydration of 5-HMF in water then yields levulinic and formic acid, as seen in Figure 1. At hydrothermal conditions $\left(>170^{\circ} \mathrm{C}\right)$, saccharides undergo intra- and inter-molecular dehydration reactions, forming aromatized clusters [16]. Once these clusters reach the supersaturation point, burst nucleation occurs, creating solid hydrochar microspheres [16].

The Sn-Beta facilitated reaction of xylose, the primary component of hemicellulose, has not been studied to the same degree as that of glucose. Holm found that in a methanol reaction solvent, pentoses like xylose yielded about $10 \%$ less methyl lactate on an inlet carbon basis [7] than comparable 
reactions of hexoses. This is due to the formation of $C_{2}$ and $C_{3}$ fragments produced through retro-aldol condensation (Figure 2), leaving only $60 \%$ of the carbon available to transform into lactic acid. Like hexoses, Brønsted acid sites competitively dehydrate the pentoses, forming furfural $[17,18]$.

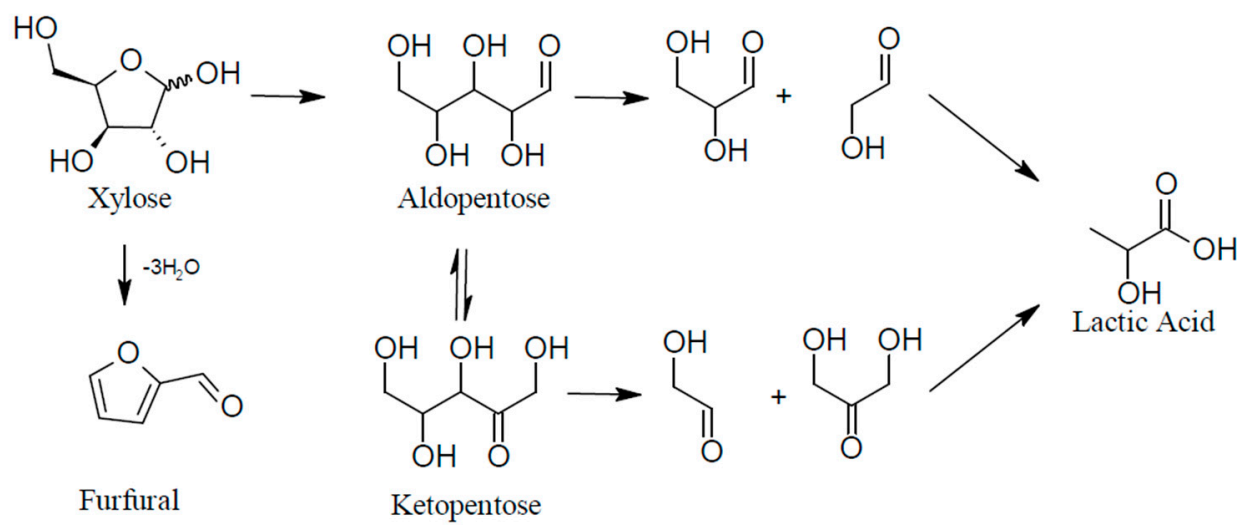

Figure 2. Reaction pathway for pentoses using Sn-Beta.

Compared to metal dopants like titanium and zirconium, tin produces the most efficient Lewis acid sites for the transformation of glucose to lactic acid when incorporated into the framework of a beta zeolite [6]. This Lewis acidity is essential for increasing the selectivity toward the desired retro-aldol reaction [6]. Additionally, a tetravalent Lewis acid, like tin, can be used to replace the trivalent aluminum within the beta-zeolite. This removes a source of Brønsted acid sites and, subsequently, decreases the selectivity of undesired dehydration reactions.

Typically, Sn-Beta can be prepared by one of two methods: hydrothermal synthesis and postsynthesis. In hydrothermal synthesis, tin ions are incorporated into the zeolite framework during nucleation. The size of the ions can inhibit the zeolite nucleation, requiring catalyst synthesis to take up to 40 days [19] and limiting the tin content on the catalyst [20]. Hydrothermal synthesis can also produce undesired metal oxide particles, providing transport limitations [15].

Conversely, postsynthesis preparation takes already formed beta zeolites and adds tin to the framework. This can be accomplished by dealuminating the zeolite with $65 \mathrm{wt} \% \mathrm{HNO}_{3}$ and then adding tin to the newly formed defect sites through solid-state ion-exchange $[19,20]$. However, this significant nitric acid requirement makes large scale production very costly. A similar postsynthesis approach to solid-state ion-exchange is impregnation. In impregnation, the beta zeolite is mixed with a tin salt in $1 \mathrm{M} \mathrm{HCl}$. This allows the zeolite to simultaneously be dealuminated and have tin added to the defect sites. This results in a significantly lower acid requirement than the traditional solid-state ion-exchange.

Various modifications can be made to Sn-Beta to improve lactic acid yield. Both adding zinc [21] and grafting an amino group [22] have been attempted to increase the basicity of the catalyst and combat the Brønsted acid sites that produce dehydration products. These attempts yielded results of significantly increasing lactic acid yield while decreasing the production of 5-HMF. Additional Lewis acids, like lead, have shown superior glucose isomerization abilities compared to tin. When combined as a dual-function catalyst, lactic acid yields increased from $22 \%$ to $52 \mathrm{wt} \%$ of inlet carbon [23]. Similarly, when indium was used for the retro-aldol reaction of fructose and tin for the subsequent triose isomerization in methanol, a pseudo methyl lactate yield of $90 \%$ was observed [24]. Yang added a metal oxide, $\mathrm{WO}_{3}$, to act as a promoter [11]. Doing so decreased silanol defects in the zeolite which catalyze the dehydration reaction, increasing methyl lactate yield from $25 \%$ to $52 \mathrm{wt} \%$ of inlet carbon.

The work reported here focused on the performance of a base Sn-Beta catalyst synthesized through impregnation. To the best of our knowledge, this catalyst preparation procedure has not previously been attempted for Sn-Beta. This study specifically looks at Sn-Beta reaction selectivity of glucose and xylose, the most naturally abundant hexose and pentose, respectively. Optimum reactions times and temperatures were initially studied using model sugar solutions. Information from the model 
reaction studies were then used to compare catalyst performance for actual biomass sources, allowing for potential discrepancies, such as $\mathrm{pH}$ and catalyst inhibitors, to be identified.

Corn stover is the most abundant biomass residue in the United States, consisting of the leftover cobs, husks, leaves, and stalks after harvest [25]. Corn stover is a lignocellulosic biomass consisting of cellulose, hemicellulose, and lignin. Both carbohydrates, cellulose and hemicellulose, can be extracted by hydrolysis yielding two primary sugars, glucose and xylose, respectively. Lignocellulosic biomass typically requires more intensive treatment to release these sugars than starch-based biomass sources, like corn kernels, making it more difficult to economically process these materials in conventional processes like fermentation [26].

Forage sorghum (Sorghum bicolor L. Moench) is a warm-season annual grass used mainly as a silage or hay crop that has been suggested as an energy feedstock rotation crop in areas where corn cannot be grown due to insufficient rainfall. Incorporating forage sorghum into existing crop rotations could provide a new source of forage and biomass feedstock while providing many ecosystem services [27].

\section{Results and Discussion}

\subsection{Catalyst Synthesis and the Evaluation of Reaction Yields from Glucose Model Solutions}

Preliminary experiments were conducted to screen potential variables and find optimum values for the catalyst synthesis using the impregnation method and for the reaction conditions associated with the conversion of glucose into lactic acid. It was determined that the most influential factors in lactic acid yield were the ratio of sugars to catalyst, the ratio of silica to alumina in the base beta-zeolite $\left(\mathrm{SiO}_{2} / \mathrm{Al}_{2} \mathrm{O}_{3}\right)$, and the temperature of the reaction. The highest yields of lactic acid were obtained at a catalyst to sugar ratio of 2.0 (10 g Sn-Beta/5 g glucose in $300 \mathrm{~mL}$ water), optimizing the concentration of Lewis acid sites for retro-aldol condensation. Similarly, using a base beta-zeolite with a high $\mathrm{SiO}_{2} / \mathrm{Al}_{2} \mathrm{O}_{3}$ ratio (300 compared to 25) diluted the presence of Brønsted acid sites, slowing the rate of dehydration reactions, which also improved reaction selectivity towards lactic acid. It was assumed that the catalyst stability would be similar to those in previous, similar studies, such as those by Kruger et al. [28]. They reported 1-2 $\mathrm{wt} \%$ dissolution of Si-Al zeolite after five hours under similar conditions.

To further increase overall reaction selectivity, the reaction temperature was varied to maximize the rate of formation of lactic acid over side-products. At a run time of $20 \mathrm{~h}$, it was found that both lactic acid yield and selectivity from glucose were maximized at $200{ }^{\circ} \mathrm{C}$ [27]. Decreasing the temperature of the reaction by decrements of $10^{\circ} \mathrm{C}$ cut lactic acid yields in half, while yields of levulinic acid, the major side reaction product, remained relatively constant. When the reaction temperature exceeded $200{ }^{\circ} \mathrm{C}$, lactic acid yield decreased, likely through an increased rate of decomposition reactions. As seen in Table 1, the maximum lactic acid yield from the preliminary experiments was $7.6 \mathrm{wt} \%$ of the initial carbon from glucose, significantly less than Sn-Beta produced through similar postsynthesis methods [22,23]. Conversely, the yield of levulinic acid exceeded that found by Xia [23]. This suggests that the impregnation synthesis method is less effective at removing alumina from the zeolite framework, creating more sites for dehydration reactions. It also suggested that additional optimization work was required.

Table 1. Preliminary yield of major acid products formed from glucose using impregnated Sn-Beta compared to postsynthesis Sn-Beta [22,23] (NR = Not Reported).

\begin{tabular}{cccc}
\hline Product & Preliminary & Kong 2018 & Xia 2018 \\
\hline Lactic Acid & $7.6 \%$ & $22 \%$ & $22.4 \%$ \\
Levulinic Acid & $19.0 \%$ & NR & $14.4 \%$ \\
\hline
\end{tabular}

Accordingly, the reaction time of $20 \mathrm{~h}$ was revisited. Preliminary trials were conducted at a reaction time of $20 \mathrm{~h}$ to ensure complete conversion of the initial monosaccharide. This high residence time, coupled with a dilute inlet sugars solution $(1.6 \mathrm{wt} \%)$, would require significant reactor volume 
on an industrial scale. Additionally, comparable studies utilized significantly shorter reaction times of $2-4 \mathrm{~h}$. Further optimization of the reaction time was thus indicated to allow for a better assessment of the reaction feasibility and comparison to similar catalyst synthesis methods.

Initial time optimization trials looked at glucose in one-hour reaction increments. As shown in Figure 3, after just one hour, lactic acid experienced a yield of about $11 \mathrm{wt} \%$ of the inlet carbon, compared to $18 \%$ for levulinic acid. Increasing the reaction time to $3 \mathrm{~h}$ resulted in a slight increase in lactic acid yield with little impact on levulinic yield. After $3 \mathrm{~h}$ and up to $5 \mathrm{~h}$, lactic acid decreased while levulinic acid yield increased. This apparent change in yield is most likely associated with modest noise within the data, which is also depicted by larger sample deviation at early reaction times. Noise can be attributed to a different catalyst batch used for each time set (1-5 h), where slight variations in the degree of dealumination and tin addition to the zeolite can slightly alter the reactivity. Accounting for this noise and high initial acid yields, it can be concluded that minor differences in catalyst preparation have a larger effect on product yield than reaction time $(>1 \mathrm{~h})$. Also of note is that shorter reaction times $(<5 \mathrm{~h})$ increased the yield of lactic acid to almost $13 \mathrm{wt} \%$ of inlet carbon compared to $7 \mathrm{wt} \%$ at $20 \mathrm{~h}$, indicating that extended time at $200{ }^{\circ} \mathrm{C}$ may lead to thermal degradation. Almost all of the target reactions appeared to be completed by one hour.

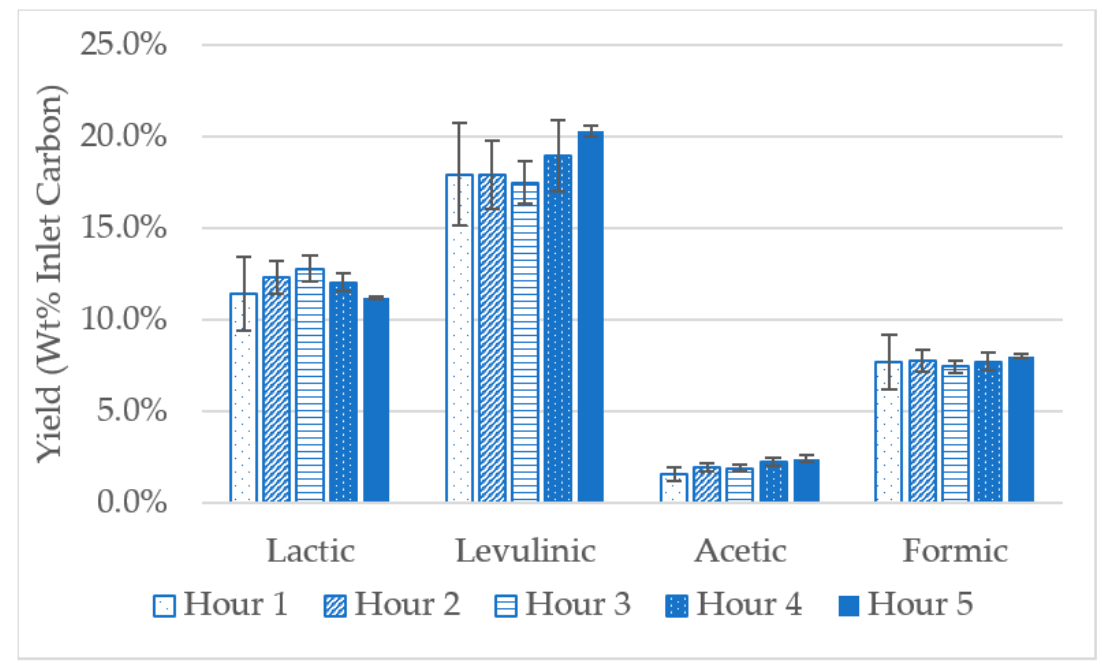

Figure 3. The effect of reaction time on organic acid yields from the Sn-Beta facilitated reaction of glucose at $200^{\circ} \mathrm{C}$, a 2:1 catalyst to sugars ratio, and no additives.

The overall yield of the four target acids was around $40 \mathrm{wt} \%$ on the inlet carbon. HPLC results suggested $100 \%$ conversion of the feed glucose with no HMF or furfural in the final product mixture. The remainder of the glucose was most likely converted into longer chain hydrocarbons that left the reactor with the catalyst in the solid phase. This material is typically labeled in the literature as a "hydrochar" [16].

\subsection{Reaction Yields from Xylose Model Solutions}

With the goal of utilizing carbohydrates from lignocellulosic biomass, the Sn-Beta reaction of xylose was investigated. Figure 4 illustrates how the acid yields for xylose vary as a function of reaction temperature in the range of $100-200^{\circ} \mathrm{C}$. Lactic acid selectivity for xylose was maximized at $180^{\circ} \mathrm{C}$ compared to a selectivity maximum of $200^{\circ} \mathrm{C}$ for glucose. The drop in yield at temperatures above $180{ }^{\circ} \mathrm{C}$ is likely due to an increased rate of xylose degradation reactions, which begin to out-pace retro-aldol condensation reactions for lactic acid formation. At temperatures below $120^{\circ} \mathrm{C}$, high levels of unreacted sugars remain, which can be attributed to the low rate of the retro-aldol condensation reaction. It is also of note that Lewis acid sites on Sn-Beta isomerize xylose. At reaction conditions of $100{ }^{\circ} \mathrm{C}$ and $20 \mathrm{~h}$, xylose is most favorably isomerized to lyxose [7]. Like xylose, lyxose is an 
aldopentose, forming the same lactic acid precursor, glyceraldehyde. The ketose in the isomerization trio, xylulose, was not observed at $20 \mathrm{~h}$ reaction times, while it was previously observed at $20 \%$ after xylose isomerization [7]. This would indicate that xylulose more readily undergoes retro-aldol condensation than its aldose isomers.

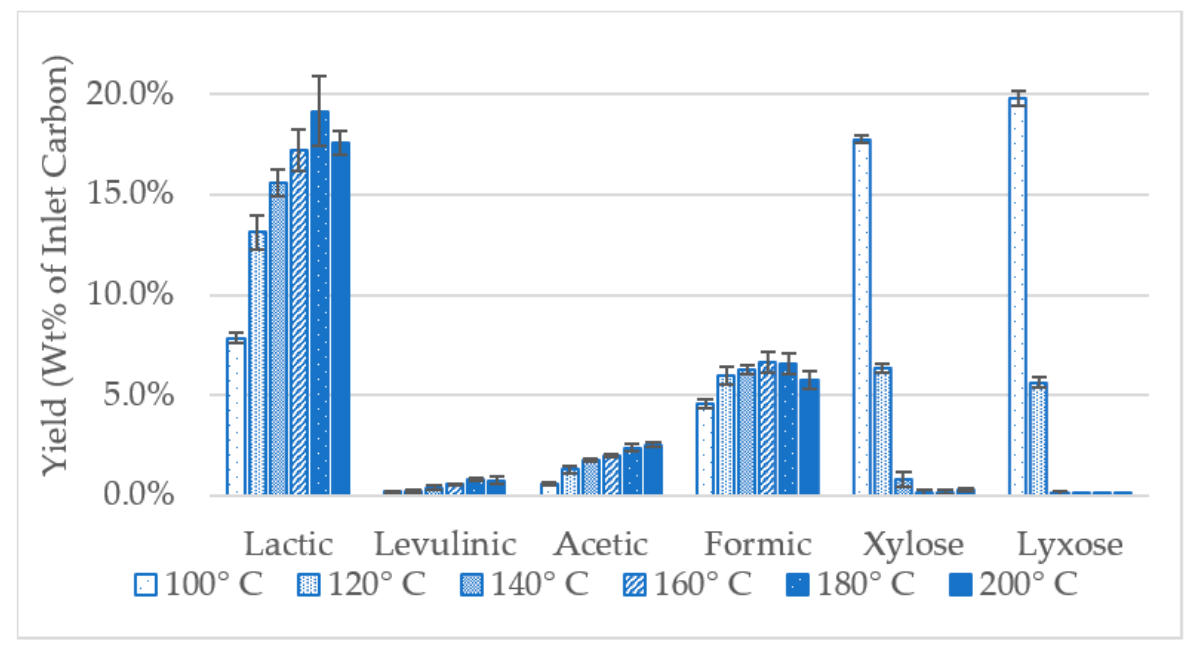

Figure 4. The effect of reaction temperature on organic acid yields from the Sn-Beta facilitated reaction of xylose at a $20 \mathrm{~h}$ batch reaction time, a 2:1 catalyst to sugars ratio and no additives.

Theoretically, the lactic acid yield from xylose should not exceed that from glucose, as pentoses are stoichiometrically limited to one lactic acid per molecule. This should result in half the lactic acid yield for xylose compared to glucose. Previous studies in methanol by Holm indicated a general increased yield for hexoses compared to pentoses, though not at the stoichiometric carbon ratio [7]. Conversely, the study presented herein suggests that aqueous reactions of pentoses have more favorable lactic acid yields. This could be a result of less effective glucose-fructose isomerization in water compared to methanol. However, when compared to glucose, aqueous fructose reactions with Sn-Beta had an $3 \%$ increase in yield of lactic acid. This is on par with results in methanol from Holm [7], suggesting that isomerization in water is comparable to methanol. Another potential reason is that pentose dehydration to furfural (Figure 2) occurs at a slower rate than that of the hexose dehydration to 5-HMF (Figure 1). This could result from the low solubility of furfural in water and the tendency of 5-HMF to split into levulinic and formic acids when partially rehydrated in acidic conditions, continually shifting the equilibrium point and increasing the hexose dehydration.

Industrial utilization of lignocellulosic biomass will likely require the conversion of mixtures of glucose and xylose. Thus, the lack of continuity between the optimum reaction temperatures of the two sugars needed to be reconciled. To aid in this reconciliation, a model solution of glucose and xylose was formulated at the expected ratio of these two primary reactants from corn stover, $65 \mathrm{wt} \%$ glucose, $35 \mathrm{wt} \%$ xylose. The solution was then reacted in water with Sn-Beta at the optimum reaction temperatures for xylose, i.e., $180{ }^{\circ} \mathrm{C}$, as shown in Figure 4, glucose, $200^{\circ} \mathrm{C}$, and the midpoint $\left(190{ }^{\circ} \mathrm{C}\right)$. As seen on Figure 5, the highest lactic acid yield occurs at $200^{\circ} \mathrm{C}$, indicating that the prevalence of glucose outweighs the higher yields from xylose.

With the lactic acid yield of a model corn stover solution optimized at $200{ }^{\circ} \mathrm{C}$, a time study of the xylose reaction was conducted. As seen in Figure 6, after only one hour, a lactic acid yield of $18.2 \mathrm{wt} \%$ of initial carbon was reached. Increasing the reaction time by an hour yielded a minimal $0.4 \%$ increase by carbon weight in lactic acid production. Trials beyond the second hour experienced large variability and no discernable change in the lactic acid yield. These results agree with previous reaction time studies of glucose model solutions where variance in the catalyst batch had a larger effect than the time of reaction after one hour. 


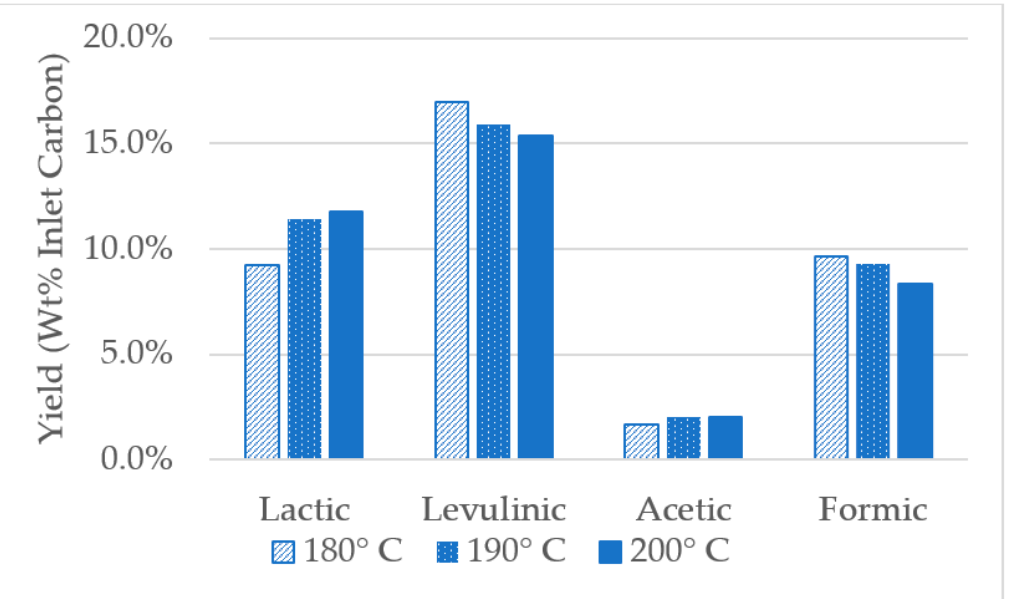

Figure 5. The effect of reaction temperature on the conversion of a corn stover model solution at $5 \mathrm{~h}$ reaction time, 2:1 catalyst to sugars ratio, and no additives. The solution contained $65 \mathrm{wt} \%$ glucose and $35 \mathrm{wt} \%$ xylose.

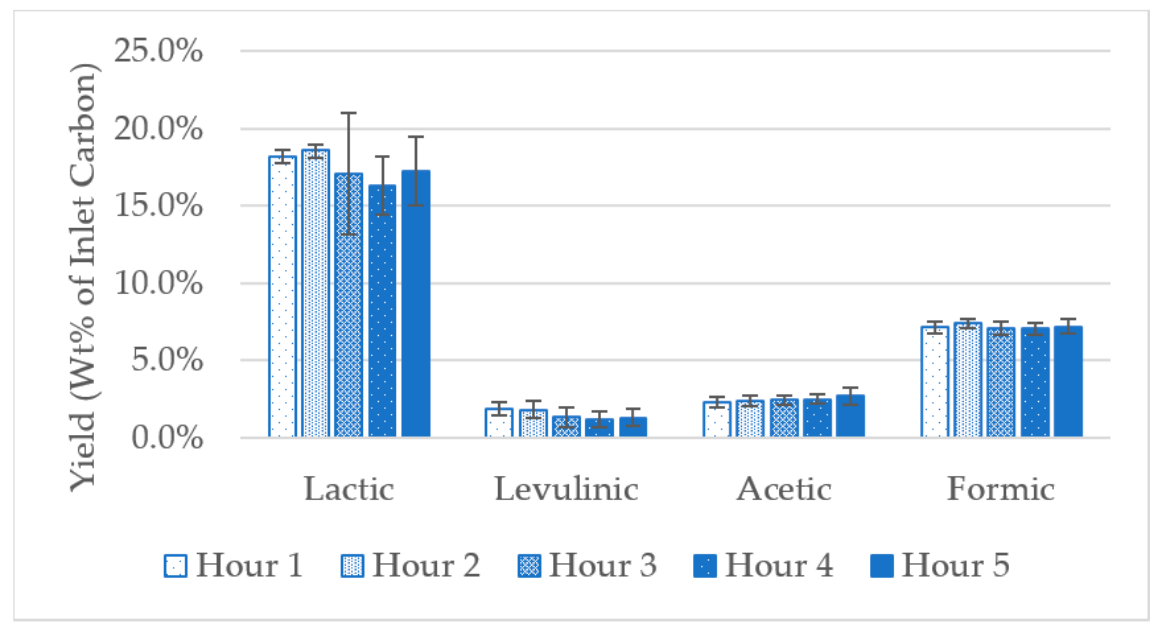

Figure 6. The effect of reaction time on organic acid yields from the Sn-Beta facilitated reaction of xylose at a reaction temperature of $200^{\circ} \mathrm{C}$, a 2:1 catalyst to sugars ratio, and no additives.

\subsection{Biomass Application}

The optimized reaction conditions were tested with two different feedstocks, corn stover and forage sorghum. Extraction of sugars from these lignocellulosic biomass sources was performed using a two-step process. The biomass was initially treated with sulfuric acid to depolymerize the hemicellulose, primarily releasing xylose. The excess sulfuric acid used for the hydrolysis was neutralized to calcium sulfate using calcium carbonate. The remaining carbohydrates, in the form of cellulose, were hydrolyzed using cellulase enzymes. Laboratory extraction experiments yielded a sugar extract solution of $49 \mathrm{wt} \%$ glucose and $51 \mathrm{wt} \%$ xylose for corn stover and $52 \mathrm{wt} \%$ glucose and $48 \mathrm{wt} \%$ xylose for forage sorghum. The reaction of each biomass hydrolysate solution with Sn-Beta at $200{ }^{\circ} \mathrm{C}$ resulted in lactic acid yields of $34 \%$ (Table 2). This differed significantly from the model solution (65\% glucose/35\% xylose) examined in Section 2.2 where a lactic acid yield of $12 \%$ was observed. Additionally, the production of levulinic acid was almost entirely suppressed. The reasons for this substantial increase in lactic acid yield are suggested by examining the initial and final $\mathrm{pH}$ of each reaction solution, as shown in Table 2. Both of the actual biomass samples started and ended at a higher $\mathrm{pH}$ than the model solution, most likely due to the presence of $\mathrm{CaSO}_{4}$ formed during the sulfuric acid neutralization step. The mechanisms for this increase are discussed in Section 2.4. 
Table 2. Comparison of yields between model sugar solutions and actual sugar solutions extracted Figure $200^{\circ} \mathrm{C}, 5 \mathrm{~h}$ reaction time, and a 2:1 catalyst to sugars ratio.

\begin{tabular}{cccc}
\hline Product & Model Lignocellulose Solution & Corn Stover Solution & Forage Sorghum Solution \\
\hline Initial pH & 2.7 & 4.5 & 5.8 \\
Final pH & 2.3 & 2.9 & 3.7 \\
Lactic Acid & $12 \%$ & $34 \%$ & $34 \%$ \\
Levulinic Acid & $15 \%$ & $1.4 \%$ & $4.0 \%$ \\
Acetic Acid & $2.1 \%$ & $10 \%$ & $8.7 \%$ \\
Formic Acid & $8.3 \%$ & $5.7 \%$ & $2.2 \%$ \\
\hline
\end{tabular}

Model Sugar Solution = expected extract sugars (65 wt \% glucose, $35 \mathrm{wt} \%$ xylose), Corn Stover Solution = Actual Corn Stover sugar extract $(49 / 51 \mathrm{wt} \%$ ratio), Forage Sorghum Solution = Actual Forage Sorghum sugar extract (52/48 wt \% ratio)].

Further study of corn stover and forage sorghum was conducted to examine the effect of the catalyst to sugar ratio on lactic acid yield. As seen in Figure 7, by reducing the sugar concentration, which effectively increases the catalyst to sugars ratio, lactic acid conversions of greater than $60 \mathrm{wt} \%$ were achieved for both biomass resources. The reason these yields exceed the yields from the model solution is most likely the result of two primary effects: (1) the change in catalyst-to-sugars ratio, and (2) the presence of $\mathrm{CaSO}_{4}$ from the hydrolysis neutralization step, which will be addressed in Section 2.4.

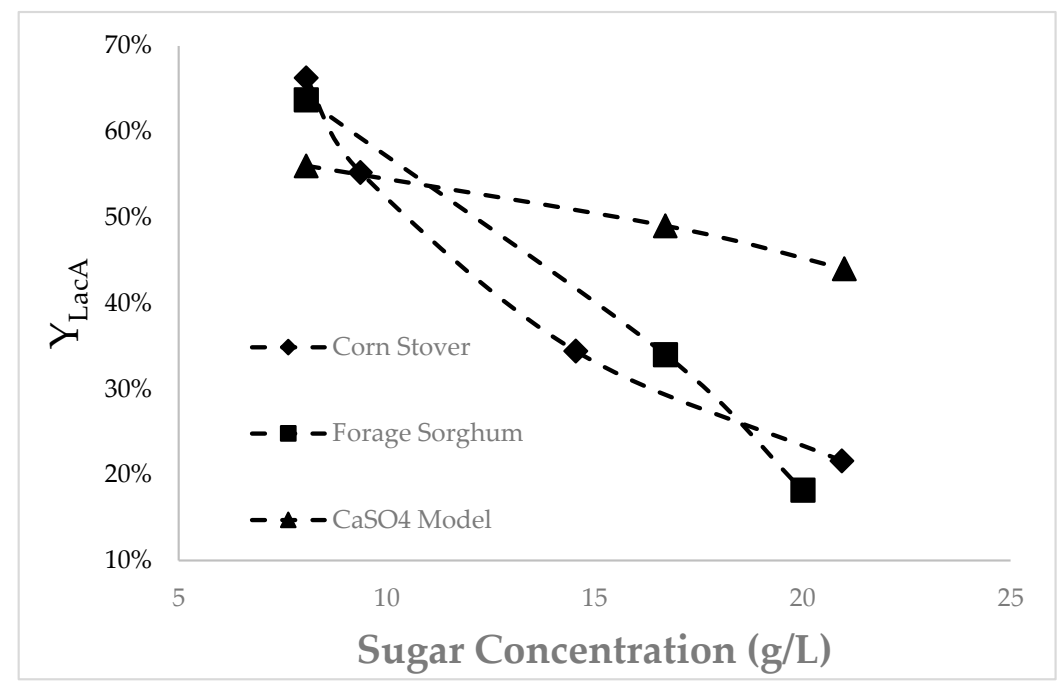

Figure 7. The sensitivity of lactic acid yield to the inlet sugar concentration at constant catalyst and solvent loadings for corn stover, forage sorghum, and model sugar solutions. Experiments were conducted at a reaction temperature of $200{ }^{\circ} \mathrm{C}$, a catalyst concentration of $33 \mathrm{~g} / \mathrm{L}$, and a reaction time of three hours. The corn stover ( $\mathrm{pH}$ 4.5) and forage sorghum ( $\mathrm{pH}$ 5.8) solutions contained residual $\mathrm{CaSO}_{4}$ from the acid hydrolysis process while the model solution was mixed with $\mathrm{CaSO}_{4}$ to a $\mathrm{pH}$ of 5.8 .

The $\mathrm{CaSO}_{4}$ model solution results shown in Figure 7 decouple these effects by feeding the model solution into the reactor at varying sugar concentrations with a $\mathrm{CaSO}_{4}$ additive that models the $\mathrm{CaSO}_{4}$ present in the actual solutions. The base case that corresponds to all of the previous optimization work is the center point, located at $16.7 \mathrm{~g} / \mathrm{L}$ sugars, i.e., a 2:1 catalyst to sugars ratio. The results shown in Figure 7 suggest that the optimum ratio is closer to 4:1. However, the change in lactic acid yield for both corn stover- and forage sorghum-derived feed solutions is much more significant and is inversely proportional to the inlet sugar concentration at constant catalyst loading and solvent quantity. This suggests that some of the facilitating acid sites are tied up during the reaction of the actual solutions. This inhibition appears to be limited to the Lewis Acid sites as the carbon yield of side-products slightly increases with increasing inlet sugar concentration (not shown). 
The most likely sources of this deactivation are electronegative elements such as $\mathrm{Cl}, \mathrm{N}$, and $\mathrm{S}$, which are present in biomass and are well known for their potential to poison metal catalysts [29]. The presence of these electronegative elements can be reduced by washing the biomass before acid hydrolysis, which has been shown to greatly decrease the ash content [29]. Another option would be to add an ion-exchange system to remove these elements before the catalytic reaction [30]. However, this ion-exchange step will likely decrease the concentration of calcium sulfate, so would need to be followed by $\mathrm{CaSO}_{4}$ addition.

\subsection{Acid Hydrolysis Neutralization and the Effect of $\mathrm{CaSO}_{4}$ on the Conversion Reaction}

Conversion of corn stover- and forage sorghum-derived sugars revealed that the presence of a salt like calcium sulfate $\left(\mathrm{CaSO}_{4}\right)$ can lead to a significant increase in lactic acid yield with a concomitant decrease in dehydration products (i.e., levulinic and formic acid). This finding is consistent with previous results reported by Tolberg [8], where the combination of $\mathrm{K}_{2} \mathrm{CO}_{3}$ with Sn-Beta resulted in a lactic acid yield of $75 \%$ by carbon weight in methanol.

One possible explanation of this phenomena is that the salt is catalyzing the retro-aldol reaction. To test this hypothesis, a series of experiments were performed at a catalyst-to-sugars ratio of 2, and a $\mathrm{CaSO}_{4}$-to-sugars ratio of 0.2 with various combinations of $\mathrm{CaSO}_{4}$ and catalyst. The results are shown in Table 3. Solely using calcium sulfate to facilitate the conversion of glucose yielded only a marginal increase in lactic acid yield ( $2.8 \mathrm{wt} \%$ of inlet carbon) compared to no additive at all. Similarly, a mixture of calcium sulfate and beta-zeolite resulted in a $2.9 \%$ lactic acid yield. This indicates that interactions between $\mathrm{CaSO}_{4}$ and the Brønsted acid active sites on the zeolite do not catalyze the retro-aldol reaction ipso facto. Further, it reconfirms that lactic acid formation is improved by the presence of tin as the Lewis acid.

Table 3. Organic acid yields from $\mathrm{CaSO}_{4}$ catalyzed reaction of glucose $\left(200{ }^{\circ} \mathrm{C}\right.$ reaction temperature, 5 $\mathrm{h}$ batch reaction time, 2:1 catalyst to sugars ratio; uncertainties are based on one standard deviation).

\begin{tabular}{cccccccc}
\hline Catalyst & Salt & $\begin{array}{c}\text { Initial } \\
\text { pH }\end{array}$ & $\begin{array}{c}\text { Final } \\
\text { pH }\end{array}$ & $\begin{array}{c}\text { Lactic } \\
\text { Acid }\end{array}$ & $\begin{array}{c}\text { Levulinic } \\
\text { Acid }\end{array}$ & $\begin{array}{c}\text { Acetic } \\
\text { Acid }\end{array}$ & $\begin{array}{c}\text { Formic } \\
\text { Acid }\end{array}$ \\
\hline- & - & 8.04 & 2.89 & $0.5 \pm 0.03 \%$ & $8.4 \pm 0.2 \%$ & $1.2 \pm 0.15 \%$ & $3.6 \pm 0.06 \%$ \\
- & $\mathrm{CaSO}_{4}$ & 8.82 & 3.49 & $2.8 \pm 0.15 \%$ & $2.1 \pm 0.13 \%$ & $4.4 \pm 0.7 \%$ & $2.7 \pm 0.16 \%$ \\
Beta & $\mathrm{CaSO}_{4}$ & 5.49 & 3.06 & $2.9 \pm 0.2 \%$ & $3.5 \pm 0.03 \%$ & $2.9 \pm 0.15 \%$ & $2.5 \pm 0.02 \%$ \\
Sn-Beta & - & 2.33 & 2.30 & $11 \pm 0.11 \%$ & $20 \pm 0.3 \%$ & $2.4 \pm 0.2 \%$ & $8.0 \pm 0.09 \%$ \\
Sn-Beta & $\mathrm{CaSO}_{4}$ & 5.41 & 2.59 & $68 \pm 0.08 \%$ & $2.0 \pm 0.2 \%$ & $3.6 \pm 0.5 \%$ & $3.2 \pm 0.3 \%$ \\
\hline
\end{tabular}

With the elimination of individual retro-aldol catalysis through calcium sulfate as an explanation, two possible reaction mechanisms remain. The first is that the disassociated calcium ion acts in tandem with tin as a second Lewis acid. It is known that tin is highly efficient in the final isomerization of trioses into lactic acid, but not as productive in the glucose-fructose isomerization and retro-aldol condensation steps [21,24]. It is possible that the Lewis acidity of calcium can more efficiently catalyze those two steps, resulting in an increased yield of lactic acid.

The second possible mechanism results from the mild Brønsted basicity of sulfate. This basicity inhibits the catalytic effect of the Brønsted acid sites which are present in the form of $\mathrm{Al}$ that was not replaced out of the catalyst framework during Sn doping. Under this mechanism, the pathway to generate levulinic acid (ketohexose-5, HMF-levulinic acid, Figure 1) is thus inhibited, increasing the reaction selectivity towards lactic acid.

To test these mechanisms, separate trials were conducted with $\mathrm{CaCl}_{2}$ and $\mathrm{NaOH}$ to isolate the Lewis acidity and Brønsted basicity, respectively. As shown in Table 4, the addition of calcium to increase Lewis acidity nearly doubled the yield of lactic acid from $11 \%$ to $21 \%$ by inlet carbon weight. This increase coincided with a slight decrease in the yield of levulinic acid, and suggests that the presence of $\mathrm{Ca}^{2+}$ has a positive effect on the lactic acid reaction pathway. Increasing the Brønsted basicity with $\mathrm{NaOH}$ resulted in an even more significant increase in lactic acid yield, i.e., to $49 \%$, 
as well as a greater reduction in levulinic acid yield. In both cases, the total conversion of the inlet glucose carbon into the four most prevalent acid products, as shown in Table 4, increases compared to the base case $\left(46 \mathrm{wt} \%\right.$ for the $\mathrm{CaCl}_{2}$ case and $60 \mathrm{wt} \%$ for the $\mathrm{NaOH}$ case compared to $40.5 \mathrm{wt} \%$ inlet carbon for the base case). This suggests that some of the glucose that converts into unidentified material that is assumed to be char is now being converted into lactic acid.

Table 4. Evaluation of Lewis acid and Brønsted base effects on Sn-Beta catalyzed reaction of glucose ( $200{ }^{\circ} \mathrm{C}$ reaction temperature, $5 \mathrm{~h}$ batch reaction time, 2:1 catalyst to sugars ratio; uncertainties are based on one standard deviation).

\begin{tabular}{lccccccc}
\hline Catalyst & Salt & $\begin{array}{c}\text { Initial } \\
\text { pH }\end{array}$ & $\begin{array}{c}\text { Final } \\
\text { pH }\end{array}$ & $\begin{array}{c}\text { Lactic } \\
\text { Acid }\end{array}$ & $\begin{array}{c}\text { Levulinic } \\
\text { Acid }\end{array}$ & $\begin{array}{c}\text { Acetic } \\
\text { Acid }\end{array}$ & $\begin{array}{c}\text { Formic } \\
\text { Acid }\end{array}$ \\
\hline Sn-Beta & - & 2.33 & 2.30 & $11 \pm 0.11 \%$ & $20 \pm 0.3 \%$ & $2.4 \pm 0.2 \%$ & $8.0 \pm 0.09 \%$ \\
Sn-Beta & $\mathrm{CaCl}_{2}$ & 2.63 & 2.08 & $21 \pm 0.99 \%$ & $16 \pm 0.03 \%$ & $2.4 \pm 0.18 \%$ & $6.4 \pm 0.01 \%$ \\
Sn-Beta & $\mathrm{NaOH}$ & 9.40 & 2.48 & $49 \pm 0.14 \%$ & $4.0 \pm 0.08 \%$ & $3.0 \pm 0.2 \%$ & $4.0 \pm 0.13 \%$ \\
Sn-Beta & $\mathrm{CaCl}_{2}+\mathrm{NaOH}$ & 6.98 & 2.30 & $56 \pm 0.4 \%$ & $3.4 \pm 1.1 \%$ & $2.9 \pm 0.7 \%$ & $0.9 \pm 0.5 \%$ \\
Sn-Beta & $\mathrm{CaCO}_{3}$ & 5.25 & 3.17 & $58 \pm 0.6 \%$ & $2.6 \pm 1.3 \%$ & $5.1 \pm 0.4 \%$ & $2.2 \pm 0.9 \%$ \\
Sn-Beta & $\mathrm{MgSO}_{4}$ & 2.88 & 2.39 & $64 \pm 0.13 \%$ & $3.5 \pm 2.2 \%$ & $3.6 \pm 0.3 \%$ & $3.1 \pm 0.13 \%$ \\
Sn-Beta & $\mathrm{CaSO}_{4}$ & 5.41 & 2.59 & $68 \pm 0.08 \%$ & $2.0 \pm 0.21 \%$ & $3.6 \pm 0.5 \%$ & $3.2 \pm 0.3 \%$ \\
\hline
\end{tabular}

Despite these increases, neither of the additives allowed the conversion reaction to reach the conversion efficiency to lactic acid observed with calcium sulfate as the additive. This suggests that both mechanisms, increasing Lewis acidity and Brønsted basicity, may contribute to the increased efficiency seen when $\mathrm{CaSO}_{4}$ is used. To test this hypothesis, calcium chloride and sodium hydroxide were both added to the reaction mixture at the concentrations used in the individual experiments, resulting in a lactic acid yield of $56 \%$. This result confirms this hypothesis but does not fully explain the even higher lactic acid conversion yields that result from using $\mathrm{CaSO}_{4}$ as an additive.

To further explore these mechanisms, the addition of similar salts, $\mathrm{CaCO}_{3}$ and $\mathrm{MgSO}_{4}$, which have slightly different properties, were examined at the same $3 \mathrm{~g} / \mathrm{L}$ concentration and at the same reaction conditions. As shown in Table 4, increasing the Brønsted basicity by replacing sulfate with carbonate $\left(\mathrm{CO}_{3}{ }^{2-}\right)$ decreased the yield of lactic acid from $68 \mathrm{wt} \%$ to $58 \mathrm{wt} \%$. This resulting yield more closely resembled that obtained from the combination of calcium chloride and sodium hydroxide, indicating that a weaker base more efficiently inhibits the effects of Brønsted acid sites present on the catalyst. Similarly, using magnesium instead of calcium to increase the Lewis acidity decreases the lactic acid yield from $68 \mathrm{wt} \%$ to $64 \mathrm{wt} \%$ inlet carbon. A slightly lower yield from magnesium indicates that it is not as complimentary to tin as calcium. Based on these results, the most likely mechanism is shown in Figure 8.

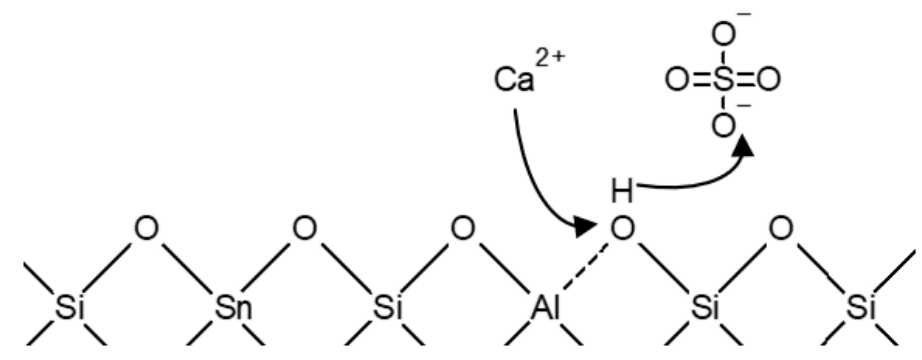

Figure 8. The proposed mechanism by which calcium sulfate modifies the Sn-Beta catalyst.

At $3 \mathrm{~g} / \mathrm{L}$, the concentrations of $\mathrm{CaCO}_{3}$ and $\mathrm{CaSO}_{4}$ exceed their solubility in water $(0.013 \mathrm{~g} / \mathrm{L}$ and $2.1 \mathrm{~g} / \mathrm{L}$, respectively). This left the possibility that the salts were catalyzing the reaction heterogeneously. Obtaining a similar yield from the highly water soluble magnesium sulfate $(350 \mathrm{~g} / \mathrm{L})$ eliminates this possibility, indicating that the salts alter the catalyst in situ to favor lactic acid production. Note, the addition rate was not optimized in these experiments, as the objective was to elucidate the mechanism first. 
The combined Sn-Beta:CaSO4 reaction system was then applied to different sugars, as seen in Table 5. Fructose, glucose, and mannose constitute ketose and aldose epimers capable of transformation to each other through aldo-keto isomerization. With only Sn-Beta as the catalyst, using fructose resulted in $120 \%$ of the lactic acid yield compared to using glucose. This was expected, since isomerization was not necessary for fructose to undergo retro-aldol condensation. With the addition of $\mathrm{CaSO}_{4}$, both aldose epimers (glucose and mannose) matched the lactic acid yield of their respective ketose (fructose). This increased favorability of the aldoses indicates that the addition of $\mathrm{CaSO}_{4}$ increases the selectivity of the initial isomerization step.

Table 5. Reaction yields of various sugars using Sn-Beta and $\mathrm{CaSO}_{4}\left(200{ }^{\circ} \mathrm{C}\right.$ reaction temperature, $5 \mathrm{~h}$ batch reaction time, 2:1 catalyst to sugars ratio; uncertainties are based on one standard deviation).

\begin{tabular}{ccccc}
\hline Sugar & Lactic Acid & Levulinic Acid & Acetic Acid & Formic Acid \\
\hline Fructose & $66 \pm 0.3 \%$ & $2.2 \pm 2.05 \%$ & $4.0 \pm 0.8 \%$ & $2.7 \pm 0.3 \%$ \\
Galactose & $55 \pm 0.05 \%$ & $1.6 \pm 0.2 \%$ & $3.6 \pm 0.15 \%$ & $3.0 \pm 0.08 \%$ \\
Glucose & $68 \pm 0.08 \%$ & $2.0 \pm 1.7 \%$ & $3.6 \pm 0.2 \%$ & $3.2 \pm 0.2 \%$ \\
Mannose & $65 \pm 0.01 \%$ & $2.3 \pm 0.02 \%$ & $3.9 \pm 0.05 \%$ & $2.5 \pm 0.08 \%$ \\
Xylose & 50 & 2.5 & 5.2 & 5.4 \\
\hline
\end{tabular}

By contrast, when using galactose, an aldohexose belonging to a separate ketose and aldose epimer trio, resulted in a lower lactic acid yield at $55 \mathrm{wt} \%$ of inlet carbon than when using glucose $(68 \mathrm{wt} \%)$. This is likely due to a steric effect based on the flipped orientation of the hydroxyl group on its fourth carbon compared to glucose. It is possible that this steric effect would increase the difficulty of breaking the bond between $\mathrm{C}_{3}$ and $\mathrm{C}_{4}$, significantly decreasing the rate of retro-aldol condensation, which could explain the lower observed yields, even in reactions of up to five hours in duration.

Using xylose as the feed reactant gave the lowest lactic acid yield of all tested monosaccharides for the Sn-Beta:CaSO4 system at $50 \mathrm{wt} \%$. This is a result of xylose being a pentose, stoichiometrically limiting its yield to $60 \%$.

\section{Materials and Methods}

\subsection{Reactants and Catalysts Materials}

Glucose (99.5\% purity), galactose (99\% purity), xylose (99\% purity), fructose ( $99 \%$ purity), mannose ( $99 \%$ purity), tin (II) chloride (98\% purity), sodium hydroxide ( $98 \%$ purity), calcium chloride $(97 \%$ purity), and magnesium sulfate ( $97 \%$ purity) were obtained from Sigma Aldrich (St. Louis, MO, USA). Hydrochloric acid at a 34-37 $\mathrm{wt} \%$ concentration, sulfuric acid at a $97 \mathrm{wt} \%$ concentration, calcium carbonate, and hemihydrate calcium sulfate were obtained from Fisher Scientific (Waltham, MA, USA). Hydrogen form, beta zeolite with a $\mathrm{SiO}_{2} / \mathrm{Al}_{2} \mathrm{O}_{3}$ ratio of 300 (CP811C-300) was purchased from Zeolyst International (Kansas City, MO, USA). Accellerase enzymes were obtained from Genencor. Ultrapure water was obtained from an in-house ultra milli-Q filter system. Compressed nitrogen (99.99\% purity) was purchased from Praxair (Grand Forks, ND, USA). Corn stover and forage sorghum were obtained from farm fields located in Eastern North Dakota, USA. Samples were ground and dried in-house.

\subsection{Catalyst Preparation}

Sn-Beta was produced using a modified postsynthesis approach. The base beta zeolite was initially calcined at $600{ }^{\circ} \mathrm{C}$ for $6 \mathrm{~h}$ to remove any impurities. Beta zeolite was then impregnated with $\mathrm{SnCl}_{2}$ in a $1.0 \mathrm{M} \mathrm{HCl}$ solution in a ratio of $10 \mathrm{~g}$ zeolite: $1 \mathrm{~g} \mathrm{SnCl}_{2}: 100 \mathrm{~mL}$ of solution. The impregnation solution was stirred at $500 \mathrm{rpm}$ overnight and then dried in an oven at $120^{\circ} \mathrm{C}$ for $48 \mathrm{~h}$. A second calcination step was then performed at $400{ }^{\circ} \mathrm{C}$ for $8 \mathrm{~h}$. 


\subsection{Batch Reactor}

All batch reaction experiments were conducted in a bench scale $500 \mathrm{~mL}$ Parr 5500 compacted series reactor (Moline, IL, USA) configured as shown in Figure 9. The head of the reactor was mounted on a stand. The full reactor vessel was lifted up to the head and sealed with a clamp. A gas inlet on the top of the reactor was used to inject nitrogen into the reactor to displace any residual oxygen in the vapor space prior to the start of each reaction. This was done to prevent side reactions as a result of oxidation. The gas was vented through an outlet valve to a fume hood. A rate adjustable motor driven stirring shaft was used to insure complete mixing of the reactants and catalyst during each reaction. A thermocouple inside the reactor was used to monitor and provide feedback on the reaction temperature. A 4848 Parr series controller was used to control the reaction temperature at $200{ }^{\circ} \mathrm{C}$ using the readout from the thermocouple. The reactor was placed within a heating jacket with an electrical resistance heater that was altered by the controller. Internal reactor pressure was monitored with an analog gauge attached to the head of the reactor.

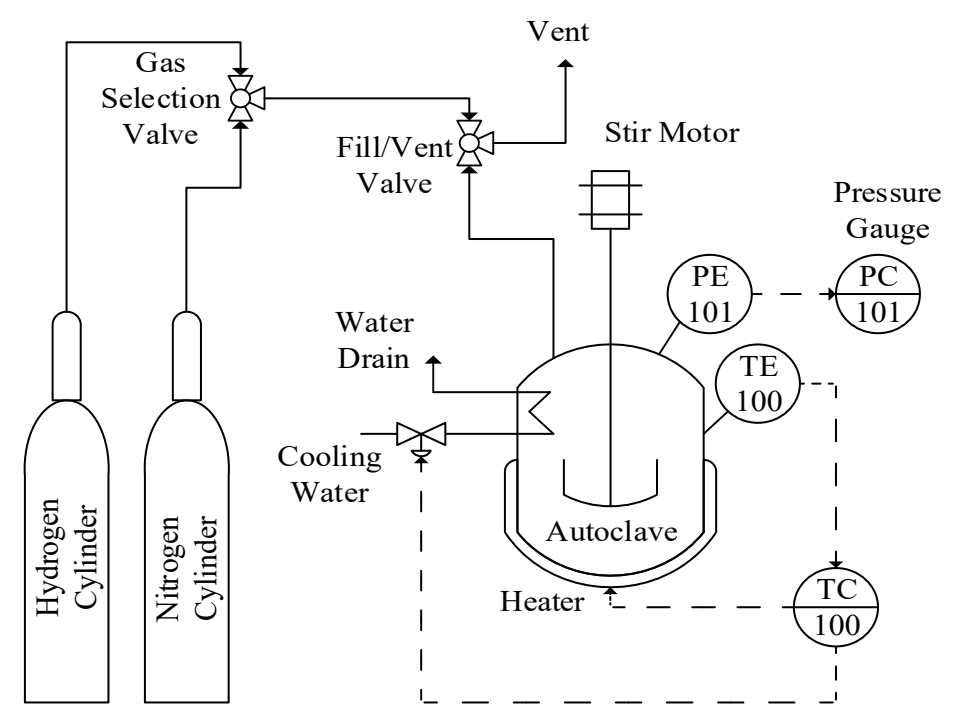

Figure 9. Simplified schematic of autoclave reactor used for all experiments.

\subsection{Reaction}

With the exception of the sugar concentrations experiments shown in Figure 7, each Sn-Beta catalytic reaction utilized ten grams of catalyst and five grams of sugars mixed in $300 \mathrm{~mL}$ of water. Water volume did not exceed this level to maintain safe reaction pressures as the $500 \mathrm{~mL}$ reactor reached the operating temperature. Once the reactor was filled and sealed, it was purged of oxygen by five pressure/vent cycles from $140 \mathrm{kPa}$ to atmosphere using lab-grade nitrogen. The reactor was then brought up to an initial pressure of $2200 \mathrm{kPa}$ using nitrogen and a five-minute pressure check was conducted.

Once it was confirmed that there were no leaks, the reactor was placed in the heating jacket. When the desired operating temperature was reached $\left(100-200^{\circ} \mathrm{C}\right)$, it was held constant for the specified reaction time. At the end of the specified time, the reaction vessel was removed from the heating jacket and the vessel was allowed to cool.

When the reaction was complete, the products were removed from the reactor, weighed, and centrifuged. The liquid product was decanted and analysed while the remaining solids were dried overnight at $60^{\circ} \mathrm{C}$. Dried solids were then weighed to estimate the accumulated mass of the hydrochar (see Section 2.1 for a definition of this material). 


\subsection{Biomass Hydrolysis}

Sugars from corn stover and forage sorghum were extracted following slightly modified conditions based on those outlined by the National Renewable Energy Laboratory (NREL) [31]. Ground and dried corn stover or forage sorghum was initially treated with $0.4 \mathrm{wt} \%$ sulfuric acid in water at a loading of $11 \mathrm{~mL} / \mathrm{g}_{\text {solids }}$ for $20 \mathrm{~min}$ at $160^{\circ} \mathrm{C}$ in a $500 \mathrm{~mL}$ Parr reactor to hydrolyse the hemicellulose. Resulting hydrolysate was neutralized with excess calcium carbonate $\left(\mathrm{CaCO}_{3}\right)$ and filtered. Collected solids after acid hydrolysis were treated with accellerase enzymes to liberate glucose from the remaining cellulose. Enzymes were loaded at a $10 \mathrm{mg}_{\text {enzymes }} / \mathrm{g}_{\text {cellulose }}$ ratio with biomass in a 20 solids $\mathrm{wt} \%$ solution. The mixture was then placed on a MAXQ 4000 shaker table (Fisher Scientific, Waltham, MA, USA) for $72 \mathrm{~h}$ at $48^{\circ} \mathrm{C}$ and $250 \mathrm{RPM}$. The resulting solution was filtered and combined with acid hydrolysate. No additional $\mathrm{CaSO}_{4}$ was added to these mixtures prior to use in the conversion reaction experiments.

\subsection{Analysis}

Organic acids were identified using GC-MS (6890NGC, 5975 MS: Agilent Technologies, Santa Clara, CA, USA). Sample injections were conducted in splitless mode at $250{ }^{\circ} \mathrm{C}$ for $0.5 \mathrm{~min}$. Separation occurred on a $30 \mathrm{~m}$ long DB-5 column, with $0.25 \mathrm{~mm}$ internal diameter and $0.25 \mu \mathrm{L}$ film thickness (J\&W Scientific, Folsom, CA, USA). Temperature was programmed to hold at $35^{\circ} \mathrm{C}$ for $1 \mathrm{~min}$., with subsequent gradients of $20^{\circ} \mathrm{C} / \mathrm{min}$ to $85^{\circ} \mathrm{C}$ and $5{ }^{\circ} \mathrm{C} / \mathrm{min}$ to $320^{\circ} \mathrm{C}$. Acids were derivatized to butyl esters using $\mathrm{BF}_{3} / 1-\mathrm{Butanol}$ following the method optimized by St'ávová [32]. The MS was used in full scan mode (50-600 m/z) at a dwell time of $50 \mathrm{~ms}$. Samples were ionized by electron ionization with an energy of $70 \mathrm{eV}$.

Liquid reaction products were quantified using High Performance Liquid Chromatography (Agilent Technologies 1200 series, Santa Clara, CA, USA). Separation occurred in an Agilent Hi-Plex H organic acid column with a mobile phase of $5 \mathrm{mM} \mathrm{H}_{2} \mathrm{SO}_{4}$ at $0.6 \mathrm{~mL} / \mathrm{min}$ and $40^{\circ} \mathrm{C}$. Each sample was measured with a refractive index detector (G1362A: Agilent Technologies, Santa Clara, CA, USA) for $45 \mathrm{~min}$.

\section{Conclusions and Recommendations for Future Work}

Sn-Beta formed through the impregnation produced $9 \%$ lower lactic acid yields on a mass fraction of inlet carbon basis than those formed through traditional postsynthesis methods. This discrepancy is likely due to the presence of Brønsted acid sites from alumina in the impregnated Sn-Beta. Maximum lactic acid yields from glucose and xylose were produced at $200^{\circ} \mathrm{C}$ and $180^{\circ} \mathrm{C}$, respectively. Using only Sn-Beta as the catalyst, xylose unexpectedly produced higher yields of lactic acid compared to glucose. This is likely due to less selectivity to the pentose dehydration products in water. Yields of both sugars appear to reach a maximum after around one hour of reaction time with fluctuations in yields in the subsequent hours likely due to variance in Sn-Beta synthesis.

Conversion of sugars extracted from corn stover and forage sorghum had significantly higher lactic acid yields with much lower levulinic acid yields than model sugar solutions. The enhanced lactic acid yield is most likely due to the presence of residual calcium sulfate from the extraction/hydrolysis steps which inhibits the production of levulinic acid and, in turn, increases the yield of lactic acid. Further investigation into the inclusion of calcium sulfate in the reaction revealed that sulfate increases Brønsted basicity and facilitates the sugars-to-lactic acid pathways. Similarly, calcium increases Lewis acidity. The combined effect of using $\mathrm{CaSO}_{4}$ as an additive provides substantial improvement in the efficiency of the initial sugar isomerization step, leading to much higher lactic acid yields (e.g., $68 \mathrm{wt} \%$ inlet carbon for glucose) compared to experiments using model sugar solutions conducted with no additive (e.g., $11 \mathrm{wt} \%$ for glucose).

The increased lactic acid yield resulting from the addition of calcium sulfate compares favorably with other modifications of Sn-Beta. An observed lactic acid carbon yield of $68 \%$ from glucose is the 
highest that is observed in water, which is the preferred solvent due to the aqueous-nature of sugar hydrolysis. Additionally, calcium sulfate is cheaply formed in the hydrolysate stream through the removal of the sulfuric acid that is utilized for acid hydrolysis.

Applying this catalytic system to monosaccharides that are closely related to glucose (fructose and mannose) yielded nearly identical lactic acid yields of around $66 \mathrm{wt} \%$. Conversely, galactose, a stereoisomer that cannot be transformed to glucose through ketose-aldose isomerization, yielded only $55 \%$ lactic acid. This was likely due to steric effects related to the positioning of the hydroxyl group on its fourth carbon. Similarly, lactic acid yield from five-carbon xylose only reached $50 \%$ due to stoichiometric limitations.

While the conversion of forage sorghum and corn stover resulted in higher lactic acid yields than pure model sugars at conditions optimized with the model compounds but with no $\mathrm{CaSO}_{4}$ addition, yields from corn stover and forage sorghum solutions were significantly lower than those from model sugars converted using the $\mathrm{Sn}-\mathrm{Beta}: \mathrm{CaSO}_{4}$ reaction system. Examining the effect of the inlet sugar concentration (i.e., the catalyst to sugars ratio), it was concluded that the original optimum catalyst-to-sugars ratio was too low (2:1 versus 4:1) for the Sn-Beta:CaSO 4 system. In addition, lactic acid yield was most likely being suppressed when processing the biomass-derived solutions due to catalyst inhibition by electronegative elements present in biomass. Instead of changing the catalyst-to-sugars ratio, it may be possible to remove the contaminants with a prewash step or ion exchange performed prior to the prereaction buffering step.

Under the best case conditions, conversions of over $65 \mathrm{wt} \%$ of the inlet carbon to lactic acid were achieved, suggesting that this reaction pathway may be attractive for commercialization. The next step in the development of this catalyst system is the translation from batch experiments using powdered catalyst to continuous experiments with a pelletized version of the catalyst. Reoptimization of the reaction conditions (temperature, residence time, pressure, etc.), catalyst stability testing, and catalyst life, fouling and regeneration tests should also be performed. Previous studies [33] have indicated that catalytic activity falls over the course of $100 \mathrm{~h}$ during continuous operation, but that activity can be restored through thermal regeneration of the catalyst. Confirmation of this conclusion should be included in the future work.

Author Contributions: A.K. wrote the majority of the material contained in the paper and performed the experimental and analytical work for the bulk of the results presented in this paper, W.S. managed all of the research projects and provided guidance and resources during the research and edited the final drafts of the paper, I.F. performed the experimental and analytical work for the forage sorghum results reported in the paper. C.K. performed experimental and analytical work for preliminary exploratory work and developed the catalyst doping method reported in the paper. All authors have read and agreed to the published version of the manuscript.

Funding: This research was funded by the North Dakota Corn Council, the United States Department of Agriculture Sungrant Program, and the North Dakota Department of Commerce SUNRISE Bioproducts Center of Excellence.

Acknowledgments: The authors wish to thank Jasmine Olesik and Shelby Amsley-Benzie who assisted with analytical work for preliminary experimental work not included in the final version of the paper.

Conflicts of Interest: The authors declare no conflict of interest.

\section{References}

1. Datta, R.; Henry, M. Lactic acid: Recent advances in products, processes and technologies-A review. J. Chem. Technol. Biotechnol. 2006, 81, 1119-1129. [CrossRef]

2. Hara, M.; Nakajima, K.; Kamata, K. Recent progress in the development of solid catalysts for biomass conversion into high value-added chemicals. Sci. Technol. Adv. Mater. 2015, 16. [CrossRef] [PubMed]

3. Conn, R.E.; Kolstad, J.J.; Borzelleca, J.F.; Dixler, D.S.; Filer, L.J.; Ladu, B.N.; Pariza, M.W. Safety assessment of polylactide (PLA) for use as a food-contact polymer. Food Chem. Toxicol. 1995, 33, 273-283. [CrossRef]

4. Lim, L.T.; Cink, K.; Vanyo, T. Processing of Poly(Lactic Acid). In Poly(Lactic Acid): Synthesis, Structures, Properties, Processing, and Applications; Auras, R., Lim, L.T., Selke, S.E.M., Tsuji, H., Eds.; John Wiley \& Sons: Hoboken, NJ, USA, 2010. 
5. Okano, K.; Tanaka, T.; Ogino, C.; Fukuda, H.; Kondo, A. Biotechnological production of enantiomeric pure lactic acid from renewable resources: Recent achievements, perspectives, and limits. Appl. Microbiol. Biotechnol. 2010, 85, 413-423. [CrossRef] [PubMed]

6. Holm, M.S.; Saravanamurugan, S.; Taarning, E. Conversion of sugars to lactic acid derivatives using heterogeneous zeotype catalysts. Science 2010, 328, 602-605. [CrossRef]

7. Holm, M.S.; Pagan-Torres, Y.J.; Saravanamurugan, S.; Riisager, A.; Dumesic, J.A.; Taarning, E. Sn- $\beta$ catalysed conversion of hemicellulosic sugars. Green Chem. 2012, 14, 702-706. [CrossRef]

8. Tolborg, S.; Sadaba, I.; Osmundsen, C.M.; Fristrup, P.; Holm, M.S.; Taarning, E. Tin-containing silicates: Alkali salts improve methyl lactate yield from sugars. Chemsuschem 2015, 8, 613-617. [CrossRef] [PubMed]

9. Werpy, T.; Pertersen, G. Top Value Added Chemicals from Biomass Volume I-Results of Screening for Potential Candidates from Sugars and Synthesis Gas; Tehnical Report for US Department of Energy: Washington, DC, USA, 2004.

10. Gallezot, P. Conversion of biomass to selected chemical products. Chem. Soc. Rev. 2012, 41, 1538-1558. [CrossRef]

11. Yang, X.; Zhang, Y.; Zhou, L.; Gao, B.; Lu, T.; Su, Y.; Xu, J. Production of lactic acid derivatives from sugars over post-synthesized Sn-Beta zeolite promoted by WO3. Food Chem. 2019, 289, 285-291. [CrossRef]

12. Cordon, M.J.; Hall, J.N.; Harris, J.W.; Bates, J.S.; Hwang, S.J.; Gounder, R. Deactivation of Sn-Beta zeolites caused by structural transformation of hydrophobic to hydrophilic micropores during aqueous-phase glucose isomerization. Catal. Sci. Technol. 2019, 9, 1654-1668. [CrossRef]

13. Moliner, M.; Roman-Leshkov, Y.; Davis, M.E. Tin-containing zeolites are highly active catalysts for the isomerization of glucose in water. Proc. Natl. Acad. Sci. USA 2010, 107, 6164-6168. [CrossRef] [PubMed]

14. Taarning, E.; Saravanamurugan, S.; Holm, M.S.; Xiong, J.M.; West, R.M.; Christensen, C.H. Zeolite-catalyzed isomerization of triose sugars. Chemsuschem 2009, 2, 625-627. [CrossRef] [PubMed]

15. Acharjee, T.C.; Lee, Y.Y. Production of Levulinic Acid from Glucose by Dual Solid-Acid Catalysts. Environ. Prog. Sustain. Energy 2018, 37, 471-480. [CrossRef]

16. Sevilla, M.; Fuertes, A.B. Chemical and structural properties of carbonaceous products obtained by hydrothermal carbonization of saccharides. Chem. A Eur. J. 2009, 15, 4195-4203. [CrossRef] [PubMed]

17. Gallo, J.M.R.; Alonso, D.M.; Mellmer, M.A.; Yeap, J.H.; Wong, H.C.; Dumesic, J.A. Production of furfural from lignocellulosic biomass using beta zeolite and biomass-derived solvent. Top. Catal. 2013, 56, 1775-1781. [CrossRef]

18. Paulino, P.N.; Reis, O.C.; Licea, Y.E.; Albuquerque, E.M.; Fraga, M.A. Valorisation of xylose to lactic acid on morphology-controlled ZnO catalysts. Catal. Sci. Technol. 2018, 8, 4945-4956. [CrossRef]

19. Hammond, C.; Conrad, S.; Hermans, I. Simple and scalable preparation of highly active lewis acidic Sn- $\beta$. Angew. Chem. Int. Ed. 2012, 51, 11736-11739. [CrossRef]

20. Li, P.; Liu, G.Q.; Wu, H.H.; Liu, Y.M.; Jiang, J.G.; Wu, P. Postsynthesis and selective oxidation properties of nanosized Sn-Beta zeolite. J. Phys. Chem. C 2011, 115, 3663-3670. [CrossRef]

21. Dong, W.J.; Shen, Z.; Peng, B.Y.; Gu, M.Y.; Zhou, X.F.; Xiang, B.; Zhang, Y.L. Selective chemical conversion of sugars in aqueous solutions without alkali to lactic acid over a Zn-Sn- $\beta$ lewis Acid-base catalyst. Sci. Rep. 2016, 6. [CrossRef]

22. Kong, L.; Shen, Z.; Zhang, W.; Xia, M.; Gu, M.Y.; Zhou, X.F.; Zhang, Y.L. Conversion of sucrose into lactic acid over functionalized sn-beta zeolite catalyst by 3-Aminopropyltrimethoxysilane. ACS Omega 2018, 3, 17430-17438. [CrossRef]

23. Xia, M.; Dong, W.J.; Gu, M.Y.; Chang, C.; Shen, Z.; Zhang, Y.L. Synergetic effects of bimetals in modified beta zeolite for lactic acid synthesis from biomass-derived carbohydrates. RSC Adv. 2018, 8, 8965-8975. [CrossRef]

24. Nemoto, K.; Hirano, Y.; Hirata, K.; Takahashi, T.; Tsuneki, H.; Tominaga, K.; Sato, K. Cooperative In-Sn catalyst system for efficient methyl lactate synthesis from biomass-derived sugars. Appl. Catal. B Environ. 2016, 183, 8-17. [CrossRef]

25. Koundinya, V. Corn Stover: What Is Its Worth? Available online: https://www.canr.msu.edu/news/corn stover_what_is_its_worth (accessed on 26 September 2020).

26. Humbird, D. Process Design and Economics for Biochemical Conversion of Lignocellulosic Biomass to Ethanol; U.S. Department of Energy: Washington, DC, USA, 2011. 
27. Kadrmas, C. Synthesis, Selection, and Optimization of Doped Zeolite Catalyst for the Nonbiolgical Production of Lactic Acid Derivatives from Biomass Derived Carbohydrates. Doctoral Dissertation, University of North Dakota, Grand Forks, ND, USA, 2014.

28. Kruger, J.S.; Nikolakis, V.; Vlachos, D.G. Aqueous-phase fructose dehydration using Bronsted acid zeolites: Catalytic activity of dissolved aluminosilicate species. Appl. Catal. General 2014, 469, 116-123. [CrossRef]

29. Lange, J.P. Renewable feedstocks: The problem of catalyst deactivation and its mitigation. Angew. Chem. Int. Ed. 2015, 54, 13186-13197. [CrossRef] [PubMed]

30. He, Y.Q.; Fang, Z.H.; Zhang, J.; Li, X.L.; Bao, J. De-ashing treatment of corn stover improves the efficiencies of enzymatic hydrolysis and consequent ethanol fermentation. Bioresour. Technol. 2014, 169, 552-558. [CrossRef] [PubMed]

31. Davis, R.; Tao, L.; Scarlata, C.; Tan, E.C.D.; Ross, J.; Lukas, J.; Sexton, D. Process Design and Economics for the Conversion of Lignocellulosic Biomass to Hydrocarbons-Dilute-Acid and Enzymatic Deconstruction of Biomass to Sugars and Catalytic Conversion of Sugars to Hydrocarbons; National Renewable Energy Laboratory: Golden, CO, USA, 2015.

32. St'avova, J.; Beranek, J.; Nelson, E.P.; Diep, B.A.; Kubatova, A. Limits of detection for the determination of mono- and dicarboxylic acids using gas and liquid chromatographic methods coupled with mass spectrometry. J. Chromatogr. B 2011, 879, 1429-1438. [CrossRef]

33. Padovan, D.; Tolborg, S.; Botti, L.; Taarning, E.; Sadaba, I.; Hammond, C. Overcoming catalyst deactivation during the continuous conversion of sugars to chemicals: Maximising the performance of Sn- $\beta$ with a little drop of water. React. Chem. Eng. 2018, 3, 155-163. [CrossRef]

Publisher's Note: MDPI stays neutral with regard to jurisdictional claims in published maps and institutional affiliations. 